\title{
Blaaskatheterisatie in historisch perspectief
}

\author{
Sophie A. Berendsen · Rosa L. Coolen · Tess van Doorn · Bertil F. M. Blok
}

Geaccepteerd op: 5 juli 2021 / Published online: 6 september 2021

(C) The Author(s) 2021

Samenvatting Dit artikel geeft een overzicht van blaaskatheterisatie in Nederland tussen 1997 en 2018. Voor het maken van het overzicht is gebruikgemaakt van een databank met declaratie-informatie over extramurale hulpmiddelenzorg onder de verzekerde bevolking. Het aantal gebruikers wordt weergegeven per 100.000 personen. Het gebruik van verblijfskatheters is toegenomen van 159 (24.734 gebruikers) in 1997 naar 315 gebruikers per 100.000 personen (54.106 gebruikers) in 2018. Het gebruik van wegwerpkatheters verdrievoudigde van 92 (14.258 gebruikers) in 1997 naar 267 per 100.000 personen (45.909 gebruikers) in 2018. In 2018 had $20,7 \%$ van de gebruikers een neurogeen en $44,9 \%$ een niet-neurogeen onderliggend lijden. De totale kosten stegen van 27,7 naar 84,4 miljoen euro. De kosten voor intermitterende katheterisatie stegen het meest: van 16,4 naar 74,6 miljoen euro. Uit dit onderzoek blijkt dat in de afgelopen 21 jaar het gebruik van verblijfskatheters en wegwerpkatheters substantieel is toegenomen. Mogelijk komt dit door de stijging van incontinentiezorg bij ouderen en dat aan richtlijnen is toegevoegd dat intermitterende katheterisatie de voorkeur heeft boven een verblijfskatheter.

Trefwoorden blaaskatheterisatie prevalentie . zorgkosten · intermitterende katheterisatie . neurogene blaas

\section{Urinary catheterization for functional bladder disorders in a historical perspective}

Abstract This article gives an overview of the history of urinary catheterization in the Netherlands from

\section{S. A. Berendsen, MSc $(\bowtie)$}

afdeling Urologie, Erasmus MC, Rotterdam, Nederland s.berendsen@erasmusmc.nl
1997 to 2018. Data were retrieved from a populationbased cohort containing information about the extramural use of medical devices in the insured population of the Netherlands. Indwelling catheter (IC) users doubled from 159 per 100,000 people $(24,734$ users) to 315 per 100,000 people $(54,106$ users). The number of persons that uses clean intermittent catheterisation (CIC) increased from 92 per 100,000 people $(14,258$ users) in 1997 to 267 per 100,000 people $(45,909$ users) in 2018. In 2018, 20.7\% had an associated neurogenic disorder and $44.9 \%$ a non-neurogenic disorder. Total expenditure on extramural use of urinary catheters increased from 27.7 to 84.4 million euros. CIC costs increased the most: from 16.4 to 74.6 million euros. This study has shown that IC and CIC use has increased substantially over the past 21 years. A possible explanation is the rise in incontinence care in older patients and the adaption of preferred CIC use in professional guidelines.

Keywords urinary catheterization - prevalence · healthcare costs - intermittent catheterization . neurogenic bladder

\section{Introductie}

Blaaskatheterisatie wordt gebruikt bij patiënten met blaasledigingsstoornissen, zoals urineretentie of -incontinentie.

Aan urineretentie kan een neurogeen of een nietneurogeen onderliggend lijden ten grondslag liggen, waarvan dwarslaesie, spina bifida of meningomyelokèle, multipele sclerose en de ziekte van Parkinson het vaakst voorkomen [1]. Voorbeelden van nietneurogeen onderliggend lijden zijn benigne prostaatobstructie, postoperatieve urineretentie of urineretentie postpartum [2]. Bij veel patiënten kan niet één onderliggende oorzaak aangewezen worden voor 
de retentie en is vaak ook sprake van verminderde detrusoractiviteit. Het is niet altijd duidelijk hoe een onderactieve detrusor is ontstaan (idiopathisch).

De voorkeursbehandeling bij patiënten met chronische urineretentie is intermitterende zelfkatheterisatie. De patiënt brengt dan vier tot zes keer per dag een katheter in om de blaas te draineren, waarna de katheter wordt verwijderd. Intermitterende zelfkatheterisatie heeft de voorkeur boven katheterisatie met een verblijfskatheter, omdat bij intermitterende zelfkatheterisatie het risico op complicaties minder is; denk aan urineweginfecties, blaasstenen en nierschade, complicaties die met een verblijfskatheter geassocieerd zijn [3, 4]. Of zelfkatheterisatie mogelijk is, is echter afhankelijk van persoonlijke factoren, zoals handfunctie en urethrale meatuspositie, en afspraken over de financiële vergoedingen voor de katheters voor eenmalig gebruik.

Bij urine-incontinentie (bij aandrang, bij inspanning of bij beide) is behandeling soms mogelijk, maar vaak wordt incontinentiemateriaal gebruikt om het urineverlies te ondervangen. Met name in verpleegtehuizen met ouderen of kwetsbare patiëntengroepen, verhoogt deze aanpak echter het risico op decubitus [5]. Vaak wordt bij die groep om die reden een verblijfskatheter aangebracht, ter preventie van decubitus of zodat kan worden begonnen met de behandeling van reeds ontstane decubitus. Bovendien verlicht een verblijfskatheter de hoge werkdruk onder het personeel. Bij mannen kan in plaats van een verblijfskatheter een condoomkatheter worden gebruikt. Deze wordt rondom de penis aangebracht. Een condoomkatheter wordt gebruikt bij urineretentie en -incontinentie, maar wordt niet geadviseerd bij een neurogene blaas met verhoogde druk, vanwege het risico op nierschade [3, 6]. De gegevens over intramuraal kathetergebruik zijn in dit onderzoek niet opgenomen.

In 2007 beliepen de kosten voor het gebruik van verblijfskatheters wereldwijd circa 380 miljoen Amerikaanse dollar [7]. Voor alle soorten blaaskatheters werd de wereldmarkt in 2020 gewaardeerd op 4,65 biljoen Amerikaanse dollar. 57\% van dit bedrag betreft wegwerpkatheters [8].

In Nederland wordt het gebruik van alle soorten blaaskatheters vergoed door de zorgverzekeraars vanuit de basisverzekering.

Recent zijn er twee artikelen gepubliceerd over het extramuraal gebruik en de kosten van blaaskatheters tussen 1997 en 2018 in Nederland in Neurourology and urodynamics en Therapeutic Advances in Urology $[9,10]$. In dit artikel worden de resultaten van deze studies kort samengevat.

\section{Methode}

In beide retrospectieve nationale databasestudies zijn gegevens gebruikt uit de databank van het Genees- en hulpmiddelen Informatie Project (GIP) van Zorginstituut Nederland (ZIN). Deze zogeheten GIPdatabank bevat declaratie-informatie van de extramurale farmaceutische en hulpmiddelenzorg en betreft middelen die zijn opgenomen in het basispakket van de Zorgverzekeringswet (ZvW) [11]. ZIN vraagt alle declaratieinformatie van de zorgverzekeraars op. De apothekers vermelden bij elke declaratie met name een ZInummer uit de G-standaard [12]. Leveranciers van medisch hulpmiddelen gebruiken met name de codering van Vektis (GPH-codes) [13]. Alle codes worden vervolgens gekoppeld aan een bijbehorende ISO9999code, en vertaald naar de monitorclassificatie van het GIP.

Tussen 1997 en 2005 bevatte de GIPdatabank alleen informatie over personen die via de Ziekenfondswet verzekerd waren (67\% van de Nederlandse bevolking). Begin 2006 werd de Zorgverzekeringswet geïmplementeerd en werd in de databank informatie van alle verzekerde personen in Nederland (dit is de voltallige Nederlandse bevolking) verwerkt. Dataverwerking geschiedt conform de Nederlandse Privacywet.
Figuur 1 Totaal aantal gebruikers van blaaskatheters in Nederland van $1997 \mathrm{t} / \mathrm{m}$ 2018

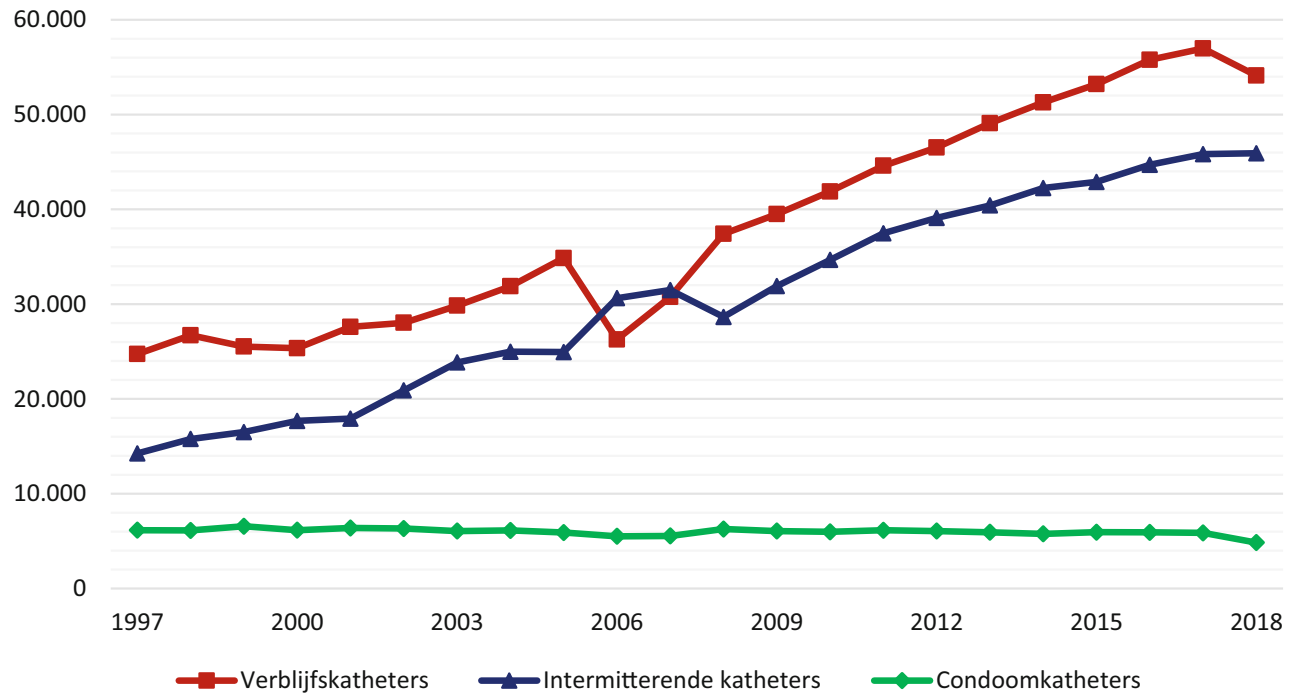


Tabel 1 Geslacht en leeftijdsverdeling van kathetergebruikers in 1997 en 2018

\begin{tabular}{|c|c|c|c|c|c|c|c|c|c|}
\hline \multirow[b]{2}{*}{ karakteristieken } & \multicolumn{3}{|c|}{ verblijfskatheters } & \multicolumn{3}{|c|}{ wegwerpkatheters } & \multicolumn{3}{|c|}{ condoomkatheters } \\
\hline & 1997 & 2018 & $\Delta(\%)$ & 1997 & 2018 & $\Delta(\%)$ & 1997 & 2018 & $\Delta(\%)$ \\
\hline totaal gebruikers & 159 & 315 & 98 & 92 & 267 & 192 & 40 & 28 & -29 \\
\hline \multicolumn{10}{|c|}{ geslacht en leeftijdsverdeling } \\
\hline $\operatorname{man}$ & 180 & 396 & 119 & 92 & 334 & 262 & 85 & 57 & -33 \\
\hline 0-25 jaar & 11 & 6 & -46 & 25 & 39 & 54 & 6 & 4 & -23 \\
\hline 25-45 jaar & 21 & 24 & 13 & 41 & 84 & 107 & 35 & 14 & -59 \\
\hline $45-65$ jaar & 122 & 159 & 30 & 111 & 272 & 145 & 73 & 37 & -49 \\
\hline 65-75 jaar & 493 & 839 & 70 & 287 & 952 & 232 & 191 & 125 & -35 \\
\hline 75-85 jaar & 1.564 & 2.464 & 58 & 453 & 1.700 & 275 & 660 & 312 & -53 \\
\hline$>85$ jaar & 4.704 & 8.133 & 73 & 719 & 2.040 & 184 & 1.544 & 743 & -52 \\
\hline vrouw & 140 & 235 & 68 & 91 & 201 & 121 & - & - & - \\
\hline 0-25 jaar & 7 & 5 & -23 & 35 & 42 & 21 & - & - & - \\
\hline 25-45 jaar & 26 & 34 & 33 & 60 & 113 & 88 & - & - & - \\
\hline 45-65 jaar & 85 & 128 & 50 & 102 & 212 & 109 & - & - & - \\
\hline $65-75$ jaar & 191 & 355 & 85 & 157 & 392 & 151 & - & - & - \\
\hline 75-85 jaar & 603 & 886 & 47 & 221 & 589 & 167 & - & - & - \\
\hline$>85$ jaar & 2.271 & 3.210 & 41 & 441 & 724 & 64 & - & - & - \\
\hline
\end{tabular}
gaan:

Op grond van beide artikelen is het volgende nage-

1. het aantal gebruikers van verblijfskatheters, wegwerpkatheters en condoomkatheters tussen 1997 en 2018;

2. de verdeling van de verschillende kathetergebruikers per geslacht en leeftijdscategorie in 1997 en 2018;

3. de verdeling van verschillende kathetergebruikers per neurogene of niet-neurogene oorzaak in 2018;

4. de kosten voor de totale bevolking voor verblijfskatheters, wegwerpkatheters, condoomkatheters en accessoires tussen 1997 en 2018;

5. de gemiddelde kosten van de verschillende typen katheters per individuele gebruiker tussen 1997 en 2018.

Op basis van de declaratie-informatie en de daaraan gekoppelde ISO-codes voor katheterverstrekking is dit onderzocht. Als eerste is een visuele controle uitgevoerd op productnaam van de katheters en is de koppeling tussen de ISO-code en de declaratie-informatie verbeterd. Zo is een aantal producten uit de ISO9999-code '92400 - Hulpmiddelen voor laten afvloeien van urine' toegewezen aan een specifiekere ISO9999-code zoals ISO9999-code '92406 - Intermitterende katheters' (= wegwerpkatheters). Ook zijn foutief gecodeerde producten verwijderd uit de analysebestanden. Vervolgens zijn alle ZI-nummers gecontroleerd aan de hand van de productinformatie in BeverOnline, de medische hulpmiddelendatabank van Nigella IT. Deze controle heeft geleid tot de uiteindelijke indeling van de medische hulpmiddelen. Op grond daarvan is vastgesteld hoeveel mensen tussen 1 januari 1997 en 31 december 2018 gebruikmaakten van katheterisatie en hoe de verdeling van de gebruikers in die jaren was naar geslacht en leeftijd.
De indeling in neurogene en niet-neurogene oorzaak vond plaats op basis van een koppeling tussen de diagnosebehandelcombinaties (DBC) die tussen 2012 en 2018 waren toegekend aan de kathetergebruikers. In 2012 werd de gemodificieerde DBC-code (DOT, DBC op weg naar transparantie) geïntroduceerd, een code gebaseerd op de diagnose en behandeling van elke individuele patiënt. Sinds die code is geïntroduceerd, kan de GIPdatabank een koppeling maken tussen de ISO-codes en DBC-codes. Een overzicht van de DBC-codes naar neurogene en niet-neurogene diagnoses is online beschikbaar als extra supplementary material bij dit artikel. Indien aan de patiënt zowel een neurogene als niet-neurogene DBC voor het kathetergebruik was toegekend, werd de gebruiker in de neurogene groep ingedeeld.

De kosten van de blaaskatheters werden gecorrigeerd voor inflatie middels de consumentenprijsindex (CPI) van het Centraal Bureau voor de Statistiek (CBS) [14]. Door het aanpassen van de kosten voor de algemene prijsontwikkeling van consumentengoederen en services, zijn de veranderingen in de katheterkosten het resultaat van volume en specifieke prijswijzigingen. Alle kosten zijn weergegeven in euro's, prijsniveau 2018.

\section{Resultaten}

Voor wie in Nederland woont of werkt, is een zorgverzekering verplicht. De GIPdatabank bevat dan ook informatie van de gehele bevolking in Nederland. Tot 2006 werd aan de GIPdatabank alleen informatie aangeleverd over personen die waren verzekerd via de Ziekenfondswet, een groep die groeide van 9,9 miljoen personen in 1997 (64\% van gehele Nederlandse bevolking) naar 10,2 miljoen personen in 2005 (63\% van gehele Nederlandse bevolking). In deze periode was 
Tabel 2 Verdeling tussen het onderliggend lijden van gebruikers en niet-gebruikers van katheters in de totale bevolking in 2018

\begin{tabular}{|c|c|c|c|c|}
\hline & $\begin{array}{l}\text { gebruikers van verblijfs- } \\
\text { katheters (\%) }\end{array}$ & $\begin{array}{l}\text { gebruikers van wegwerp- } \\
\text { katheters }(\%)\end{array}$ & $\begin{array}{l}\text { gebruikers van wegwerp- en } \\
\text { verblijfskatheters (\%) }\end{array}$ & totaal aantal gebruikers (\%) \\
\hline neurogeen & $8.904(18,1)$ & $9.579(23,3)$ & $1.197(25,0)$ & $19.680(20,7)$ \\
\hline niet-neurogeen & $20.407(41,4)$ & $20.070(48,8)$ & $2.272(47,4)$ & $42.749(44,9)$ \\
\hline onbekend $^{\mathrm{a}}$ & $20.004(40,6)$ & $11.480(27,9)$ & $1.322(27,6)$ & $32.806(34,4)$ \\
\hline totaal & $49.314(100)$ & $41.129(100)$ & $4.791(100)$ & $95.234(100)$ \\
\hline
\end{tabular}

de rest van de bevolking verzekerd via private zorgverzekeraars, die aan de GIPdatabank geen informatie aanleverden. In 2006 werd de Zorgverzekeringswet van kracht en werden de gegevens van iedereen geregistreerd, namelijk van 16,2 miljoen personen in 2006 (99\% van de Nederlandse bevolking), tot 17,1 miljoen personen in 2018 (100\% van de Nederlandse bevolking).

\section{Prevalentie van kathetergebruik in de extramurale setting}

De prevalentie van kathetergebruik in de extramurale setting is uitgedrukt in het aantal gebruikers per 100.000 personen van de algemene Nederlandse bevolking. Het totaal aantal gebruikers werd berekend met de populatiedata die door het Centraal Bureau van Statistiek (CBS) zijn geregistreerd tussen 1997 en 2018 [15].

Het aantal personen per 100.000 dat blaaskatheters gebruikte steeg van 291 in 1997 naar 610 in 2018. Specifiek voor verblijfskatheters steeg dit aantal van 159 in 1997 naar 315 in 2018. In absolute getallen was deze stijging meer dan een verdubbeling: van 24.734 naar 54.106 gebruikers (fig. 1). Het aantal personen per 100.000 dat wegwerpkatheters gebruikte verdrievoudigde in dezelfde periode bijna van 92 naar 267, wat in absolute aantallen een stijging was van 14.258 naar 45.909 gebruikers.

Het aantal personen per 100.000 dat zowel verblijfskatheter als wegwerpkatheters gebruikte steeg van 16 in 1997 (absoluut: 2.499 gebruikers) naar 28 in 2018 (absoluut: 4.791 gebruikers).

Het aantal personen per 100.000 dat condoomkatheters gebruikte nam juist af van 40 in 1997 (6.158 gebruikers) naar 28 in 2018 (4.841 gebruikers). In tab. 1 wordt de groei per geslacht en leeftijdscategorie weergeven. Het gebruik van verblijfskatheters en wegwerpkatheters is boven de 25 jaar in elke leeftijdscategorie toegenomen. Het gebruik van condoomkatheters nam juist af in elke leeftijdscategorie. Uit tab. 1 is af te lezen dat het risico op katheterisatie met de leeftijd toeneemt. 0,8\% van de 65- tot 75-jarige mannen gebruikte minimaal één verblijfskatheter in 2018. In hetzelfde jaar was het risico om een verblijfskatheter te krijgen voor mannen boven de 85 jaar $8,1 \%$.

\section{Etiologie}

Van alle 95.234 kathetergebruikers in 2018, had 20,7\% (19.680 gebruikers) een neurogene oorzaak als onderliggend lijden en 44,9\% (42.749 gebruikers) een nietneurogene oorzaak. Van de overige 34,4\% (32.806 gebruikers) was na 2012 geen DBC geregistreerd, waardoor geen onderliggend lijden kon worden bepaald (tab. 2).

Van personen die in 2018 een verblijfskatheter gebruikten, was in $18,1 \%$ (8.904 gebruikers) van de gevallen een neurogeen onderliggend lijden geregistreerd, in 41,4\% (20.407 gebruikers) een nietneurogeen onderliggend lijden en in 40,6\% (20.004 gebruikers) van de gevallen was het onderliggend lijden niet geregistreerd. Van gebruikers van wegwerpkatheters was in 23,3\% (9.579 gebruikers) van de gevallen een neurogeen onderliggend lijden en in $48,8 \%$ (20.070 gebruikers) van de gevallen een niet-neurogeen onderliggend lijden geregistreerd; in $27,9 \%$ (11.480 gebruikers) van de gevallen was het onderliggend lijden niet geregistreerd.

Van de personen die in 2018 zowel verblijfskatheters als wegwerpkatheters gebruikten, had 25\% (1.197 gebruikers) een onderliggend neurogene aandoening, $47,4 \%$ (2.272 gebruikers) een niet-neurogene aandoening en van $27,6 \%$ (1.322 gebruikers) was de oorzaak onbekend.

\section{Kosten van kathetergebruikers}

Alle kosten zijn gecorrigeerd voor inflatie en uitgedrukt in euro. Uitgebreide informatie over urineopvangzakken was alleen beschikbaar na 2001. Totale uitgaven aan extramuraal kathetergebruik steeg van 27,7 miljoen euro in 1997 naar 84,4 miljoen euro in 2018. Totale kosten voor urineopvangzakken nam af van 17,2 miljoen euro in 2001 naar 5,3 miljoen euro in 2018. De kosten voor de verschillende type katheters zijn weergegeven in fig. 2. De kosten voor verblijfskatheters stegen van 6,0 miljoen euro in 1997 naar 6,7 miljoen euro in 2018 en voor de bijbehorende urineopvangzakken daalden van 14,1 miljoen euro in 2001 naar 4,4 miljoen euro in 2018. De voor wegwerpkatheters stegen van 16,4 miljoen euro in 1997 naar 74,6 miljoen euro in 2018. De kosten voor de bijbehorende urineopvangzakken daalden van 3,1 miljoen 
Figuur 2 Totale kosten van blaaskatheters in $\mathrm{Ne}$ derland van $1997 \mathrm{t} / \mathrm{m}$ 2018, gecorrigeerd voor inflatie

Figuur 3 Verdeling van de totale kosten van blaaskatheters en accessoires in Nederland in 2018
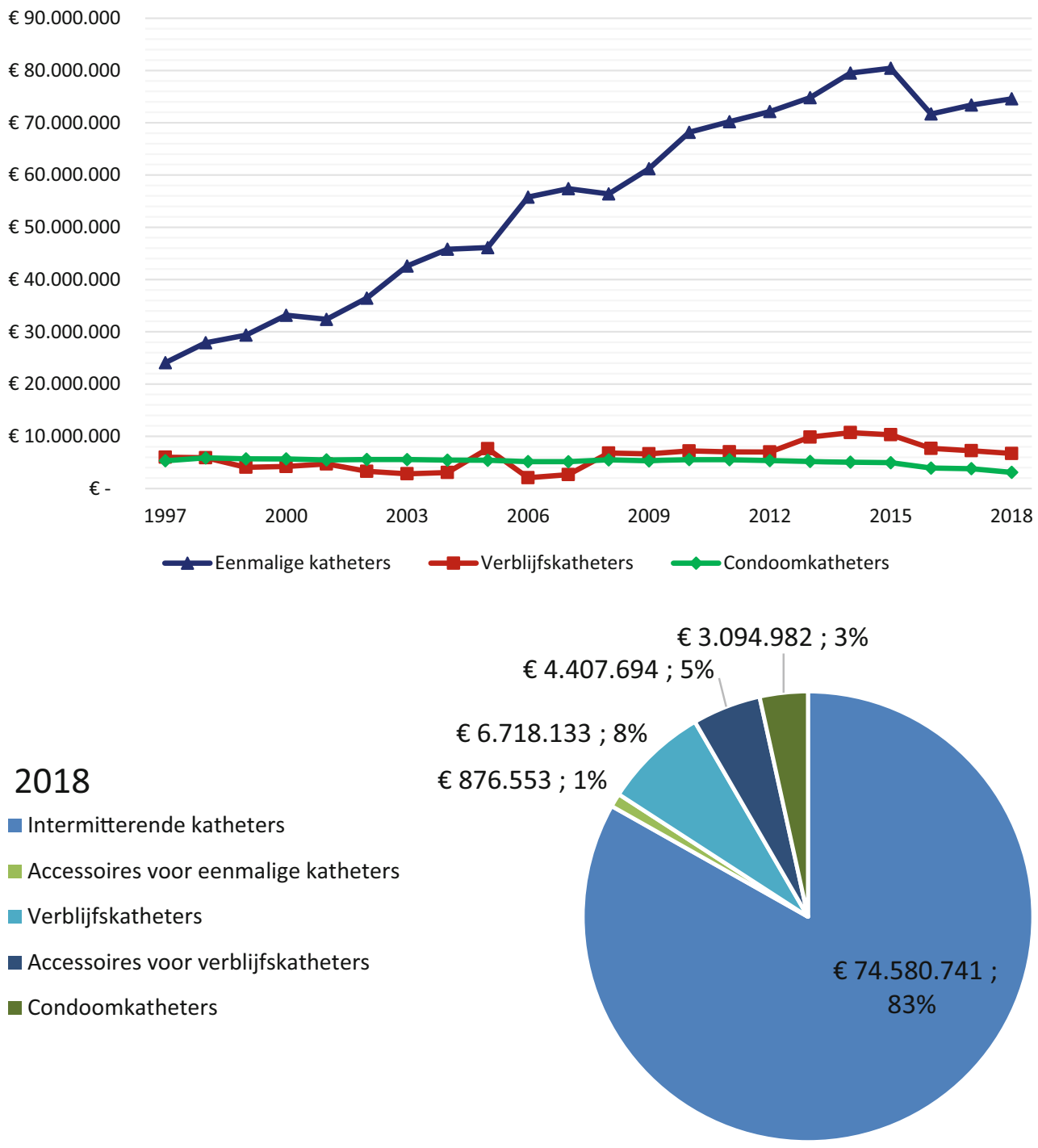

euro in 2001 tot 0,9 miljoen euro in 2018. De totale kosten voor condoomkatheters daalden van 5,3 miljoen euro in 1997 naar 3,1 miljoen euro in 2018.

In fig. 3 worden de kosten per gebruiker weergegeven. Jaarlijkse kosten per gebruiker van een verblijfskatheter daalden van 242 euro in 1997 naar 124 euro in 2018. De kosten van de bijbehorende urineopvangzakken daalden van 510 euro in 2001 naar 81 euro in 2018. De jaarlijkse kosten per gebruiker van wegwerpkatheters stegen van 1.151 euro in 1997 naar 1.624 euro in 2018; de kosten voor de bijbehorende urineopvangzakken daalden van 175 euro in 2001 naar 19 euro in 2018. Jaarlijkse kosten voor gebruikers van een condoomkatheter daalden in van 865 euro in 1997 naar 639 euro in 2018.

\section{Discussie}

Blaaskatheterisatie is een veelgebruikte therapie voor patiënten met een gestoorde blaasfunctie. Deze studie heeft gekeken naar het extramurale gebruik en de kosten van blaaskatheters in Nederland tussen 1997 en 2018. De resultaten laten een duidelijke stijging zien in het gebruik en de kosten van verblijfskatheters en wegwerpkatheters. Het gebruik van verblijfskatheters verdubbelde in de afgelopen 20 jaar. In diezelfde periode verdriedubbelde zelfs het gebruik van wegwerpkatheters. Een mogelijke verklaring voor de verdubbeling van verblijfskatheters is de toegenomen incidentie van urine-incontinentie door de vergrijzing. In het Verenigd Koninkrijk, zochten 1,3 miljoen mensen hulp voor incontinentie klachten tussen 2006 en 2007. In de jaren 2010-2011 was dit aantal gestegen naar 2,3 miljoen mensen. Het is bewezen dat het risico op incontinentie toeneemt met de leeftijd, $14 \%$ van alle 64- tot 69 -jarigen heeft last van incontinentie. Bij 85-plussers heeft zelfs $45 \%$ last van incontinentieklachten [16]. Uit de resultaten van de bovengenoemde studies blijkt dat het risico op katheterisatie ook stijgt met de leeftijd, met name bij mannen. 0,8\% van de 65- tot 75-jarige mannen heeft in $2018 \mathrm{mi}$ nimaal een verblijfskatheter gehad. In hetzelfde jaar kreeg $8,1 \%$ van de mannen van 85 en ouder een verblijfskatheter. 


\title{
Hier staat een advertentie.
}

\author{
$c$ bohn

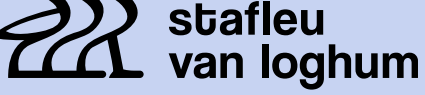 \\ Springer Media
}

Houten 2021 


\title{
Hier staat een advertentie.
}

\author{
$c$ bohn

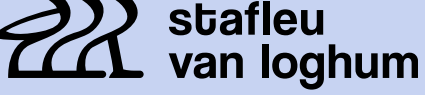 \\ Springer Media
}

Houten 2021 
De sterke stijging in het gebruik van wegwerpkatheters toont het belang van deze therapie aan voor mensen met een onderactieve blaas. Het bevestigt dat niet elke patiënt geschikt is voor alternatieve behandelingen zoals sacrale neuromodulatie. Daarnaast tonen deze resultaten voor het eerst de omvang van de neurogene en niet-neurogene patiëntenpopulatie in Nederland aan. Eerder uitgevoerde studies betroffen vaak kleine cohorten over neurogene patiënten waarbij de prevalentie sterk varieerde [3]. Wij beschreven het aantal katheter gebruikers met een neurogeen en niet-neurogeen onderliggend lijden in 2018. Van alle gebruikers gebruikte 20,7\% een katheter vanwege een neurogeen onderliggend lijden. Bijna de helft van deze groep patiënten gebruikte alleen een verblijfskatheter. Dit relatief hoge aantal kan worden verklaard door urge-incontinentie bij neurogene blaaspatiënten of door een verminderde handfunctie bij deze groep. Bij 34,4\% van alle kathetergebruikers kon geen onderliggende oorzaak worden bepaald. Individuen die voor 2012 het laatst een ziekenhuisbezoek aflegden, werd geen DBC-code geregistreerd en zij konden daarom niet worden ingedeeld in een neurogeen of niet-neurogeen onderliggend lijden. Een precieze verdeling kon daarom niet worden gemaakt. Dit heeft mogelijk geleid tot een onderschatting van de neurogene blaaspopulatie. Daarnaast is het niet bekend of DBC-codes worden geregistreerd na het uitvoeren van urodynamisch onderzoek, daarom is voorzichtigheid geboden bij de interpretatie van alle geregistreerde DBC-codes als onderliggende aandoening.

De kosten van extramuraal medische hulpmiddelen stijgen in Nederland, waarbij urinekatheters in de top vier van hoogste uitgaven staan [17]. Nederland is verantwoordelijk voor $2,6 \%$ van de wereldwijde marktomvang voor urinekatheters, die geschat wordt op 3,4 miljard dollar in 2015 [7]. In 2018 was $84 \%$ (75,5 miljoen euro) van de totale uitgaven aan extramurale urinekatheters en opvangzakken voor zelfkatheterisatie.

Deze resultaten kunnen niet volledig gegeneraliseerd worden naar andere landen. In Nederland en de meeste landen van de Europese Unie worden de meeste katheters vergoed door zorgverzekeraars. Helaas zijn de dekkingsniveaus voor medische verzekeringen in sommige landen lager, met name in lage inkomenslanden. Sociaaleconomische aspecten, zoals de prijs van de katheter, gezondheidsnormen of het aantal katheters dat nodig is in een bepaalde periode, zijn factoren die van invloed kunnen zijn op de keuze van het kathetertype. Om deze reden kan deze studie een bevooroordeelde 'optimale situatie' vertegenwoordigen voor landen zonder volledige verzekeringsdekking.

Onze resultaten zijn echter wel in lijn met het gebruik van verblijfskatheters in Engeland, Wales en Noord-Ierland. In deze landen gebruikte $3 \%$ van de mensen een verblijfskatheter, wat vergelijkbaar is met de uitkomsten uit onze studie. Bewoners van verzorgingstehuizen gebruikten daar in $13 \%$ van de gevallen een verblijfskatheter [18]. We vermoeden dat het gebruik van verblijfskatheters en condoomkatheters ook substantieel hoger is in de Nederlandse zorginstellingen. Hoewel we veel moeite hebben gedaan om een geschikte database over het intramurale gebruik van blaaskatheters te vinden, is dit niet gelukt. Daarom bevat deze studie alleen informatie over het extramuraal (poliklinische) gebruik.

De belangrijkste beperking van deze studie is dat het gebruik van blaaskatheters in ziekenhuizen en zorgcentra niet in de analyse is meegenomen. Dit kan resulteren in een onderschatting, vooral ten aanzien van verblijfskatheters en condoomkatheters. De gegevens over extramuraal kathetergebruik zijn echter uniek, aangezien het de eerste studie is met een op de populatie gebaseerd cohort.

Hoewel het huidige onderzoek is gebaseerd op de totale niet-gehospitaliseerde en niet-geïnstitutionaliseerde Nederlandse bevolking, laten de bevindingen een aanzienlijke groei zien in de afgelopen twee decennia in gebruik en kosten voor verblijfskatheters en wegwerpkatheters. Een vijfde van alle gebruikers had een neurogene onderliggende aandoening en bijna de helft van die patiënten gebruikte alleen verblijfskatheterisatie. Deze informatie is nooit eerder beschreven. Slechts een deel van de kostenstijging voor katheters was te wijten aan prijsverhogingen van fabrikanten, terwijl de prijzen van urineopvangzakken duidelijk daalden. De belangrijkste reden van de stijging in gebruik van verblijfskatheters en wegwerpkatheters lijkt de toename van incontinentie bij ouderen en de toevoeging van zelfkatheterisatie als voorkeursbehandeling in professionele richtlijnen.

Open Access This article is distributed under the terms of the Creative Commons Attribution 4.0 International License (http://creativecommons.org/licenses/by/4.0/), which permits unrestricted use, distribution, and reproduction in any medium, provided you give appropriate credit to the original author(s) and the source, provide a link to the Creative Commons license, and indicate if changes were made.

\section{Literatuur}

1. Ginsberg D. The epidemiology and pathophysiology of neurogenic bladder. Am J Manag Care. 2013;19(10 Suppl):s191-s6.

2. Selius BA, Subedi R. Urinary retention in adults: diagnosis and initial management. Am Fam Physician. 2008;77(5):643-50.

3. Blok B, Castro Diaz D, Del Popolo G. EAU guidelines on neuro-urology. 2020. Beschikbaar via https://uroweb.org/ guideline/neuro-urology/\#3_1. Geraadpleegd op: 31 mei 2012.

4. Lapides J, Diokno AC, Silber SJ, Lowe BS. Clean, intermittent self-catheterization in the treatment of urinary tract disease. J Urol. 1972;107(3):458-61.

5. Ouslander JG, Palmer MH, Rovner BW, German PS. Urinary incontinence in nursing homes: incidence, remission and associated factors. JAm Geriatr Soc. 1993;41(10):1083-9. 


\section{Artikel}

6. Blok B, de Kort L, Heesakkers JP. Multidisciplinaire richtlijnen neurogene blaas. 2012. Beschikbaar via https://dwarslaesie.nl/wp-content/uploads/2016/ 09/Richtlijnen-behandeling-NEUROGENE_BLAAS.pdf. Geraadpleegd op: 31 mei 2021.

7. Feneley RC, Hopley IB, Wells PN. Urinary catheters: history, current status, adverse events and research agenda. J Med Eng Technol. 2015;39(8):459-70.

8. Research GV. Urinary catheters market size, share \& trends analysis report by application (BPH \& Prostate Surgeries, Urinary Incontinence), by product (intermittent, external), by region (APAC, Europe), and segment forecasts, 2021-2028: grand view research. 2021. Beschikbaar via https://www.grandviewresearch.com/industryanalysis/urinary-catheters-market. Geraadpleegd op: 31 jun 2021.

9. Berendsen SA, van Doorn T, Blok BFM. Trends in the use and costs of intermittent urinary catheters in the Netherlands from 1997 to 2018: a population-based observational study. Neurourol Urodyn. 2021;40(3):876-82.

10. BerendsenSA, Doorn Tvan, BlokBFM. Urinary catheterization from 1997 to 2018: a Dutch population-based cohort. TherAdv Urol. 2021;13:17562872211007625.

11. GIPdatabank. Genees-en hulpmiddelen InformatieProject Databank. 2021. https://www.gipdatabank.nl/. Geraadpleegd op: 30 jun 2021.

12. G-standaard. Databank met informatie over zorgproducten: Z-index. 2021. https://www.z-index.nl/z-index. Geraadpleegd op: 30jun2021.
13. Vektis. Declaratie hulpmiddelen-GPH code. 2021. https:// www.vektis.nl/standaardisatie/standaarden/LH307-5.2. Geraadpleegd op: 30 jun 2021.

14. CBS.nl. Consumentenprijzen; prijsindex 2015=100. 2021. Beschikbaar via https://opendata.cbs.nl/statline/\#/CBS/ $\mathrm{nl} /$ dataset/83131NED/line?ts=1622212023891. Geraadpleegd op: 28 mei 2021.

15. CBS.nl. Bevolking; kerncijfers. 2021. Beschikbaar via https://opendata.cbs.nl/statline/\#/CBS/nl/dataset/ 37296ned/table?ts=1622212107365. Geraadpleegd op: 28 mei2021.

16. Harari D, Rogers J, Eustice S, Colley W. Continence care services: England 2013. London: Parliament;2013.

17. Zorginstituut Nederland, Genees en Hulpmiddelen Informatie Project Databank. Top 10 van hulpmiddelen op basis van de totale kosten in 2020. 2020. Beschikbaar via https://www.gipdatabank.nl/databank? infotype $=$ h\&label=00- totaal\&tabel_h_00-totaal=R_05 top10_hm\&geg=tk\&spec=\&item =home. Geraadpleegd op: 31 mei2021.

18. Wagg A, Potter J, Peel P, Irwin P, Lowe D, Pearson M. National audit of continence care for older people: management of urinaryincontinence. Age Ageing. 2008;37(1):39-44.

Sophie A. Berendsen, arts-onderzoeker

Rosa L. Coolen, arts-onderzoeker

Tess van Doorn, arts-onderzoeker

dr. Bertil F.M. Blok, uroloog 